\title{
One Step Synthesis of Au Nanoparticles Supported on Graphene Oxide Using an Eco-Friendly Microwave-Assisted Process
}

\author{
Adriana MARINOIU*, Radu ANDREI, Irina VAGNER, Violeta NICULESCU, \\ Felicia BUCURA, Marius CONSTANTINESCU, Elena CARCADEA
}

\begin{abstract}
National Research and Development Institute for Cryogenics and Isotopic Technologies - ICSI Rm. Valcea, Uzinei Street No. 4, P.O. Box Râureni 7, 240050, Râmnicu Vâlcea, Romania
\end{abstract}

crossref http://dx.doi.org/10.5755/j01.ms.26.3.21857

Received 15 October 2018; accepted 27 February 2019

\begin{abstract}
Microwave (MW) assisted processes become more and more used in the synthesis and alteration of graphene materials. This technique brings some various advantages compare to the classical ones because it is a green, low-cost, environmentally-friendly process. Moreover, no toxic solvent is necessary for the production of high-quality graphenebased materials. This eco-friendly process has recently received important attention as uniform, fast, energy efficient and scalable approach to synthesis noble metals supported on graphene oxide. A facile, rapid, low cost and efficient method to prepare gold supported on reduced graphene oxide $(\mathrm{Au} / \mathrm{rGO})$ is presented in this paper. The $\mathrm{Au} / \mathrm{rGO}$ samples were produced using the microwave power of $800 \mathrm{~W}$ and two temperatures, 60 and $80^{\circ} \mathrm{C}$, for 30 minutes only. The physical characterization showed that the Au nanoparticles were grafting on the graphene surface. Additionally, the nitrogen adsorption-desorption isotherms show a high pore volume and specific surface suggesting that a larger mesoporous volume have been achieved. The presence of interconnections between micropores and mesopores is beneficial to the mass transport process in PEMFC by creating a facile access of the reactants. Moreover, the accelerated stability tests (AST) of the catalysts showed that the catalysts are stable and no remarkable change in the shape of the voltammetry curve could be observed after 200 cycles.

Keywords: microwave irradiation, graphene, gold nanoparticles.
\end{abstract}

\section{INTRODUCTION}

The potential applications of nano-carbon materials as catalyst supports and electronic materials have attracted many interests due to their morphologies that can be designed as needed [1]. Many methods have been developed to synthesize nano-carbon materials, like chemical vapor deposition (CVD), arc-discharge, epitaxial growth and bottom-up synthesis [2,3]. Anyhow, increased temperature treatment is generally necessary to obtain the desired crystallinity for these kinds of materials which is correlated with their characteristics [4]. Recently, microwave irradiation become more and more used in the synthesis and alteration of graphene materials [5-7] and in the conception of the graphene compounds in liquid phase [8-10].

Microwave (MW) heating is a technique that brings some advantages, like rapidity, regularity, clarity to obtain smaller and well dispersed nanoparticles [11]. This method has received significant attention as a novel, bright method to decrease the constitution of "re-graphitized" carbon zone of graphene $[12,13]$. In a classical microwave reaction in liquid phase, the microwave irradiation ensures a reverse temperature variation. The effect of potential superheating and the selective wave-absorption of polar solvents or substrates cause this technique to be energy-efficient and time-saving $[11,14]$. The heating produced by microwave irradiation and interfered by the dielectric relaxation or ionic conduction, assure a manner to heat homogeneously

\footnotetext{
* Corresponding author. Tel.: +40250 732744; fax: +40250 732746.

E-mail address: adriana.marinoiu@icsi.ro (A. Marinoiu)
}

a system and a very important factor is that the ability of the wave-absorption of the sample can heat selectively the substrates. Whereas the microwave irradiation is a sharp and adsorption-selective heating method [15], it is also adequate for solid phase reactions [16, 17]. During this technique no mechanical stirring or energy loss to the environment are observed. The materials that absorb microwave may be efficiently and homogeneously heated [15].

Microwave heating is estimated as an attractive way in organic compounds and inorganic materials synthesis for reducing the time of the reaction. Moreover, this technique eliminates secondary reactions improving the efficiency and the yield of a distinctive synthetic protocol [18]. Recently, some authors reported the synthesis of graphene through reduction of graphene oxide using microwave heating $[19,20]$.

Generally, the catalysts for fuel cells are synthesized through chemical reduction method using mainly the ethylene glycol (EG). $\mathrm{NaBH}_{4}$ is a powerful reducing agent which might be efficient at low temperature and more exactly at room temperature, in spite of several some drawbacks since the particle size and dispersion of the metal nanoparticles cannot be controlled. In comparison with $\mathrm{NaBH}_{4}$, ethylene glycol (EG) involve a superior reaction temperature, usually $>120{ }^{\circ} \mathrm{C}$ and increased reaction time $(>4 \mathrm{~h})$. An alternative method to these can be utilization of a mixture of $\mathrm{NaBH}_{4}$ and EG who put together the advantage of each one, like powerful reducing mediator of $\mathrm{NaBH}_{4}$ and better dispersion assured by EG. Utilizing this alternative method smaller nanoparticles with superior dispersion can be obtained [21, 22]. 
Through actual methods of synthesis, using of microwaves has attracted considerable attention, due to extremely easy handling, as well as to its various applications in preparation of nanostructured materials. The main advantages of this synthesis processes is connected especially to low cost and high efficiency, since microwave energy is absorbed directly by the reactants instead of being absorbed by the vessel or reactor, as in conventional techniques. Using microwaves synthesis, the uniform heating could provide more homogeneous nucleation and shorter crystallization times. Moreover, the microwave hydrothermal processes has recently obtained a significant recognition due to the feasibility of controlling the materials structure and the reaction selectivity by simply controlling temperature, reaction pressure and reaction time.

This paper reports the synthesis, using microwaveassisted hydrothermal synthesis, of $\mathrm{Au}$ nanoparticles (AuNP). The novelty of this work is the synthesis method itself, meaning the application of microwave for obtaining of $\mathrm{Au}$ nanoparticles supported on graphene oxide, instead taking into account the conventional methods up to date.

\section{EXPERIMENTAL}

\subsection{Materials}

Graphene oxide was purchased from Abalonyx (Norway), Sodium Borohydride, 98\%, powder, from Alfa Aesar, Hydogen tetrachloroaurate (III) hydrate (chloroauric acid), Premion $(\mathrm{HAuCl} \bullet \times \mathrm{xH} 2 \mathrm{O})$, crystalline, from Alfa Aesar, Distilled water.

\subsection{Methods}

Synthesis starts from graphene oxide. $250 \mathrm{mg}$ of graphene oxide powder was dispersed in distilled water using 4 wt.\% graphene. Sodium borohydride, (aqueous solution $8.1 \mathrm{wt} . \%$ ) in distilled water was added on the graphene oxide dispersion, then the mixture was homogenized for 30 minutes in the ultrasonic bath. Chloroauric acid (solution $1 \mathrm{wt} . \%$ ) was then added in the obtained dispersion and treated again in ultrasonic bath for 30 minutes. After the second ultrasonic step, the dispersion was heated at microwave oven at $100{ }^{\circ} \mathrm{C}$ and $800 \mathrm{~W}$ power for 30 minutes. The synthesis product was cooled down, washed on fritted disk funnel with a mixture of $1: 1$ in volume water to ethyl alcohol, until the washing solution was free from chloride ions, then the slurry was dried in a laboratory freeze dryer.

\subsection{Physical characterizations}

Fourier-transform infrared spectroscopy (FT-IR) was carried out on Agilent Cary 630 FTIR system. This spectrometer is versatile, innovative, and intuitive, providing superior quantitative and qualitative information for routine analysis of solids, liquids, and gases. With a wide range of sample interfaces and high performing optics, the compact Agilent Cary 630 FTIR gave accurate results. The system includes standard transmission Diamond ATR. The chemical composition of the samples was determined using Flash 2000/Thermo Scientific equipment. Samples are placed in tin nails $(1-3 \mathrm{mg})$. For the quantification of $\mathrm{C}, \mathrm{N}$ and $\mathrm{H}$ it was used the combustion method at $950{ }^{\circ} \mathrm{C}$. For oxygen determination, the equipment uses the pyrolysis method at $\mathrm{T}=1050{ }^{\circ} \mathrm{C}$. The gas is separated on the SM5A column (molecular sieve) and also detected by the TCD. Au content (wt.\%) and trace metals $(\mathrm{K}, \mathrm{Mn}$ ) analysis were performed with an atomic absorption spectrometer VARIAN AA 240 FS after sample mineralization in a microwave digestion system MILLESTONE 1200 MEGA. The standard addition method was used as calibration method. $0.1 \mathrm{~g}$ sample was weighed in the crucible of modified Teflon. Over the samples the following reactive were added: $2 \mathrm{ml}$ conc. $\mathrm{HF}$, $2 \mathrm{ml}$ conc. $\mathrm{HClO}_{4}$ and $2 \mathrm{ml}$ conc. $\mathrm{H} 2 \mathrm{SO} 4$. A blank control was run for purity reagents. The power program chosen was: $50 / 250 \mathrm{~W}-50 / 400 \mathrm{~W}-100 / 500 \mathrm{~W}$.

The specific surface areas of the samples were determined using the BET method by performing nitrogen sorption measurements using a Quantachrome Autosorb IQ equipment. The adsorption and desorption experiments were done at $77 \mathrm{~K}$ after initial pre-treatment of the samples by degassing at $115^{\circ} \mathrm{C}$ for $4 \mathrm{~h}$.

\subsection{Microwave setup}

The Microwave heating was performed with a MARS 6 system which delivers approximately 1800 watts of microwave energy at a frequency of $2450 \mathrm{MHz}$. All reagents were added to the microwave reactor, without any previous treatment, and were heated at $60{ }^{\circ} \mathrm{C}$ (obtained sample was encoded $\mathrm{Au} / \mathrm{rGO}-60)$ and respectively $80^{\circ} \mathrm{C}$ (obtained sample was encoded $\mathrm{Au} / \mathrm{rGO}-80$ ). The obtained sol was centrifuged and washed several times with deionized water and dried at $80{ }^{\circ} \mathrm{C}$. The as-prepared materials were characterized as materials with potential electrocatalytic activity.

\subsection{Electrode preparation}

Catalyst ink was prepared by dispersing $5.0 \mathrm{mg}$ of $\mathrm{Au} / \mathrm{rGO}-60$ and $\mathrm{Au} / \mathrm{rGO}-80$ catalysts, isopropyl alcohol (Sigma-Aldrich), deionized water and $26 \mu \mathrm{l}$ of $5 \mathrm{wt} . \%$ Nafion solution (Ion Power), dispersed and sonicated in cold-water for $45 \mathrm{~min}$. Thin catalyst film was obtained by dropping $10 \mu \mathrm{l}$ of the catalyst ink onto the polished gold disk electrode (4 $\mathrm{mm}$ diameter) followed by drying at $40{ }^{\circ} \mathrm{C}$.

\subsection{Electrochemical measurements}

The electrochemical measurements were performed using a VersaSCAN electrochemical workstation including two potentiostats VersaSTAT F and $3 \mathrm{~F}$ from Princeton Applied Research and the supplied electrical devices, software, and gold disk electrode, was used.

A classical three electrodes cell was used for the cell measurements, using an $\mathrm{Ag} / \mathrm{AgCl}$ electrode and a Pt wire as the reference and counter electrodes, respectively. The prepared electrodes were tested on a solution of $5 \mathrm{mM}$ $\mathrm{K}_{3}\left[\mathrm{Fe}(\mathrm{CN})_{6}\right]$ in distilled water, using $\mathrm{KCl}$ as indifferent electrolyte so that the concentration was $100 \mathrm{mM}$. The cyclic voltammograms (CV) experiments were performed for the gold disk electrode between -0.35 and 0.8 or $1 \mathrm{~V}$ vs $\mathrm{Ag} / \mathrm{AgCl}$ with a sweep rate of $50 \mathrm{mVs}^{-1}$.

The electrochemical surface area was evaluated from Randles-Sevcik equation: 


$$
I_{p}=2.69 \times 10^{5} \times z^{3 / 2} \times S \times D^{1 / 2} \times c \times v^{1 / 2}
$$

where $I p$ is the peak current $(\mathrm{A}) ; z$ is the number of exchanged electrons; $S$ is electrochemical surface area $\left(\mathrm{cm}^{2}\right) ; D$ is the diffusion coefficient of the electroactive species $\left(\mathrm{cm}^{2} \cdot \mathrm{s}^{-1}\right), c$ is the concentration of the electroactive species $\left(\mathrm{mol} \cdot \mathrm{L}^{-1}\right)$ and $v$ is the scan rate $\left(\mathrm{V} \cdot \mathrm{s}^{-1}\right)$.

\section{RESULTS AND DISCUSSION}

\subsection{Structural and chemical analysis}

In order to investigate the structure and to characterize the porosity of doped graphene, the nitrogen adsorptiondesorption isotherms were recorded using BrunauerEmmett-Teller (BET) method. The adsorption/desorption isotherm of $\mathrm{Au} / \mathrm{rGO}$ sample are presented in Fig. 1. The $\mathrm{N}_{2}$ isotherms show characteristics of type IV with a uniform H1 hysteresis loop at a relative pressure range of $0.45-0.95$, with steep adsorption/desorption branches, suggesting that there are good transport properties among the micropores and mesoporous channels in $\mathrm{Au} / \mathrm{rGO}$ sample. The hysteresis loop is mainly due to the several mechanisms that take place in pores between capillary condensation and evaporation processes.

The BET surface area was estimated of $244.3 \mathrm{~m}^{2} \cdot \mathrm{g}^{-1}$ (corresponding to $\mathrm{Au} / \mathrm{rGO}-60$ ) and $177.8 \mathrm{~m}^{2} \cdot \mathrm{g}^{-1}$ (corresponding to $\mathrm{Au} / \mathrm{rGO}-80$ ). The obtained BET surface area of prepared $\mathrm{Au} / \mathrm{rGO}$ samples indicates a decrease of specific surface area during the proposed technologies, comparatively to our results obtained in the case of graphene sheets $\left(795 \mathrm{~m}^{2} \cdot \mathrm{g}^{-1}\right)$ (Table 1).

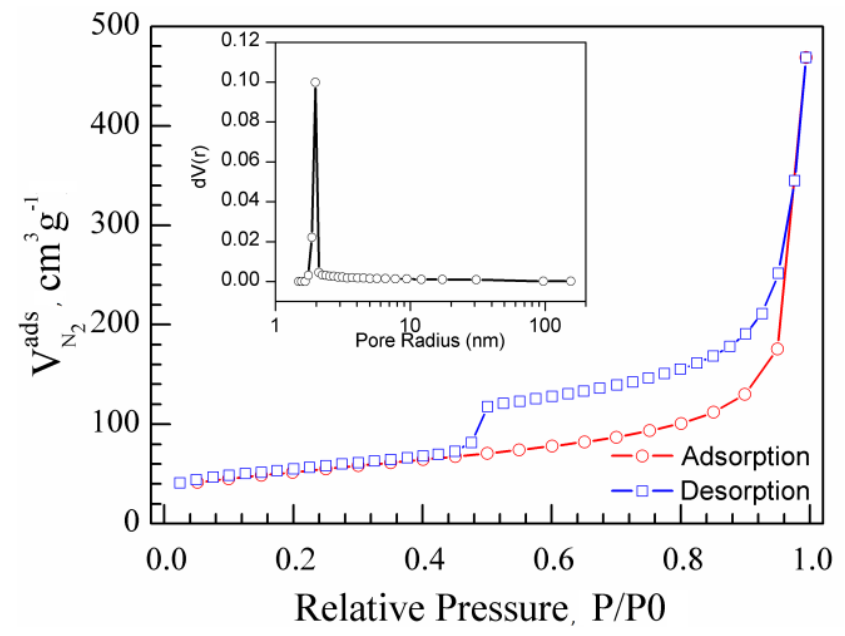

Fig. 1. Nitrogen sorption isotherms of Au/rGO-60 sample

The pore size distribution curve was estimated from desorption branches of isotherm using Barrett-JoynerHalenda $(\mathrm{BJH})$ method and was presented as inserted plot. $\mathrm{BJH}$ desorption average pore radius of $\mathrm{Au} / \mathrm{rGO}-80$ shows a unimodal peak (19.693 $\AA$ ) slightly higher to the pore radius of $\mathrm{Au} / \mathrm{rGO}-60(19.676 \AA)$. At the same time the total pore volume of $\mathrm{Au} / \mathrm{rGO}-60\left(1.049 \mathrm{~cm}^{3} \cdot \mathrm{g}^{-1}\right)$ is much bigger than $\mathrm{Au} / \mathrm{rGO}-80\left(0.74 \mathrm{~cm}^{3} \cdot \mathrm{g}^{-1}\right)$, suggesting that, for the last one, a part of mesopores were blocked during the grafting process. The analysis of pore size distribution also confirmed the coexistence of micro and mesopores, providing a hierarchical porous structure in prepared catalysts. The existence of the mesopores and interconnections are important for the mass transport process in PEMFC by creating a facile access of the reactants, and a more favorable path for break and conveyance of water product through graphene structure.

Table 1. Textural properties of Au/rGO samples

\begin{tabular}{|c|c|c|c|}
\hline Sample & $\mathrm{S}_{\text {BET }, \mathrm{m}^{2} \cdot \mathrm{g}^{-1}}$ & Pore volume, $\mathrm{cm}^{3} \cdot \mathrm{g}^{-1}$ & $\mathrm{Dv}(\mathrm{r}), \AA$ \\
\hline $\mathrm{Au} / \mathrm{rGO}-60$ & 244.3 & 1.049 & 19.676 \\
\hline $\mathrm{Au} / \mathrm{rGO}-80$ & 177.8 & 0.74 & 19.693 \\
\hline
\end{tabular}

The chemical composition of $\mathrm{rGO}$ and $\mathrm{Au} / \mathrm{rGO}$ samples are presented in Table 2. The analysis were performed using atomic absorption and elemental analysis. The higher concentration of $\mathrm{Au}$ obtained could be explained taking into account the different reaction temperature used for the sample preparation.

Table 2. Chemical compositional analysis

\begin{tabular}{|l|c|c|c|c|c|c|}
\hline \multirow{2}{*}{ Sample } & \multicolumn{5}{|c|}{ Elemental analysis \% } & $\begin{array}{c}\text { Atomic } \\
\text { absorption } \\
\%\end{array}$ \\
\cline { 2 - 7 } & $\mathrm{C}$ & $\mathrm{H}$ & $\mathrm{N}$ & $\mathrm{S}$ & $\mathrm{O}$ & $\mathrm{Au}$ \\
\hline $\mathrm{rGO}$ & 72.25 & 0.64 & 0.49 & - & 16.41 & - \\
\hline $\mathrm{Au} / \mathrm{rGO}-60$ & 55.10 & 1.01 & 0.37 & 0.47 & 10.29 & 15.71 \\
\hline $\mathrm{Au} / \mathrm{rGO}-80$ & 47.95 & 0.95 & 0.36 & 0.27 & 8.70 & 23.56 \\
\hline
\end{tabular}

The FT-IR spectra of Au/rGO-60 and Au/rGO-80 samples gave similar curves (Fig. 2). The spectrum presents the $\mathrm{C}-\mathrm{O}$ stretching vibration that originates from the remaining oxygen functionalities at $1250 \mathrm{~cm}^{-1}, \mathrm{C}=\mathrm{C}$ stretching vibrations assigns to the carbon atoms of the graphene layer at $1590 \mathrm{~cm}^{-1}, \mathrm{C}=\mathrm{O}$ stretching vibration, significantly weakened after graphene reduction at $1723 \mathrm{~cm}^{-1}$, and at $\sim 3450 \mathrm{~cm}^{-1}$ due to the $\mathrm{O}-\mathrm{H}$ stretching mode of intercalated water.

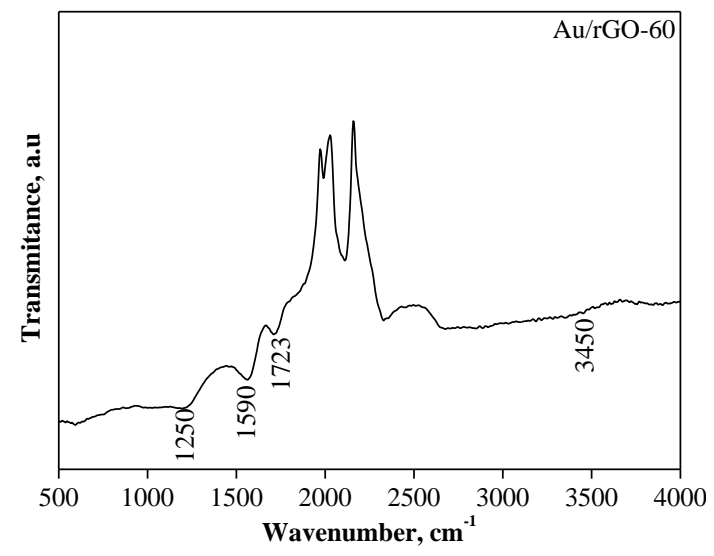

Fig. 2. FT-IR spectra of Au/rGO-60

\subsection{Electrochemical studies of Au/rGO catalysts}

In order to observe the redox activity of $\mathrm{Au}$ based catalysts, cyclic voltammetry measurements using the prepared electrodes were performed. The electrochemical performance of the electrodes is achieved to measure their efficiency using electrochemical redox couple ferro/ferricyanide and electroactive zones, respectively.

The accelerated stability test (AST) of Au based catalysts is performed by using $\mathrm{CV}$ measurement. The $\mathrm{CV}$ are evaluated from 1 to 200 cycles with a potential window of $-0.35-0.8 \mathrm{~V}$ and $-0.35-1.0 \mathrm{~V}$ vs. $\mathrm{Ag} / \mathrm{AgCl}[23]$. 
In Fig. 3 and Fig. 4 are presented the cyclic voltammograms of $\mathrm{Au} / \mathrm{rGO}-60$ and $\mathrm{Au} / \mathrm{rGO}-80$ catalysts after 200 cycles in the potential field of $-0.35-0.8 \mathrm{~V}$ vs $\mathrm{Ag} / \mathrm{AgCl}$.

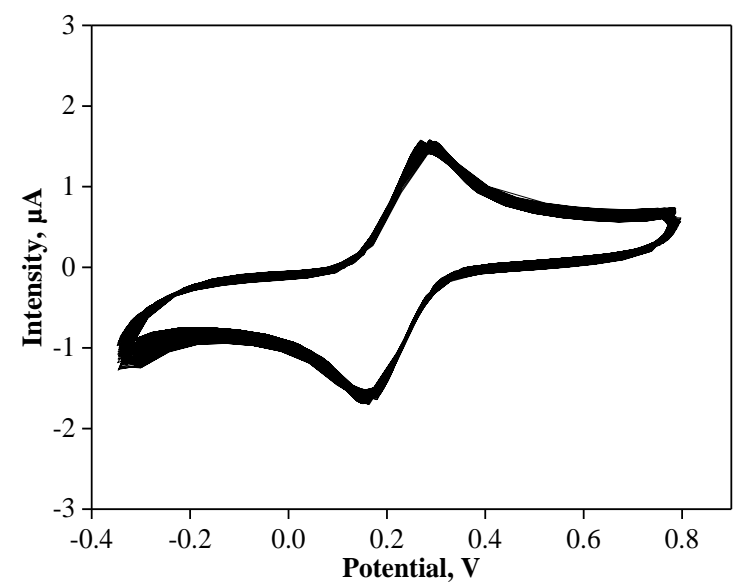

Fig. 3. The cyclic voltammograms of Au/rGO-60 catalyst after 200 cycles at $50 \mathrm{mV} \mathrm{s}^{-1}$

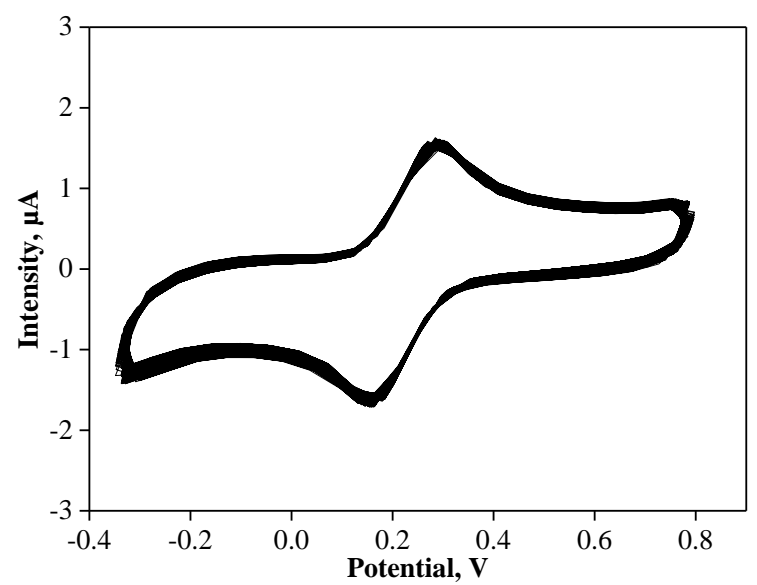

Fig. 4. The cyclic voltammograms of Au/rGO-80 catalyst after 200 cycles at $50 \mathrm{mV} \mathrm{s}^{-1}$

It can be observed that well defined and reproductible anode and cathode peaks related to $\left.\mathrm{Fe}(\mathrm{CN})_{6}{ }^{3-} / \mathrm{FeCN}\right)_{6}{ }^{-}$redox couple with a quasi-reversible behaviour are obtained after 200 cycles. Moreover, for both catalysts the adsorption and desorption of hydrogen can be observed at 0.18 and $0.325 \mathrm{~V}$. Similar values were obtained in ref [24].

In Table 3 the electrochemical surface areas (ECSA) for our catalysts in the potential range $-0.35-0.8 \mathrm{~V}$ are shown. Increasing the synthesis temperature a slight difference is observed in the ECSA. In the same time no significative differences are distinguished after 200 cycle.

Table 3. The $\mathrm{S}_{\mathrm{ECSA}}$ of the of Au/rGO prepared samples

\begin{tabular}{|c|c|c|}
\hline \multirow{2}{*}{ Sample } & \multicolumn{2}{|c|}{ Electrochemical surface area, $\mathrm{cm}^{2}$} \\
\cline { 2 - 3 } & First cycle & 200 cycle \\
\hline $\mathrm{Au} / \mathrm{rGO}-60$ & $9.288 \times 10^{-3}$ & $9.607 \times 10^{-3}$ \\
\hline $\mathrm{Au} / \mathrm{rGO}-80$ & $9.694 \times 10^{-3}$ & $9.867 \times 10^{-3}$ \\
\hline
\end{tabular}

Fig. 5 presents a comparison between gold disk electrode, $\mathrm{rGO}, \mathrm{Au} / \mathrm{rGO}-60$ and $\mathrm{Au} / \mathrm{rGO}-80$ at $50 \mathrm{mV} \cdot \mathrm{s}^{-1}$ scan rate. As we can easily observe, in the case of gold disk electrode (black line) there is no charge accumulation due to the presence of a smooth and flat surface. In the presence of the reduced graphene (red line), the electric double layer is caused to a non-uniform surface that leads to charge accumulation at different levels on the sample.

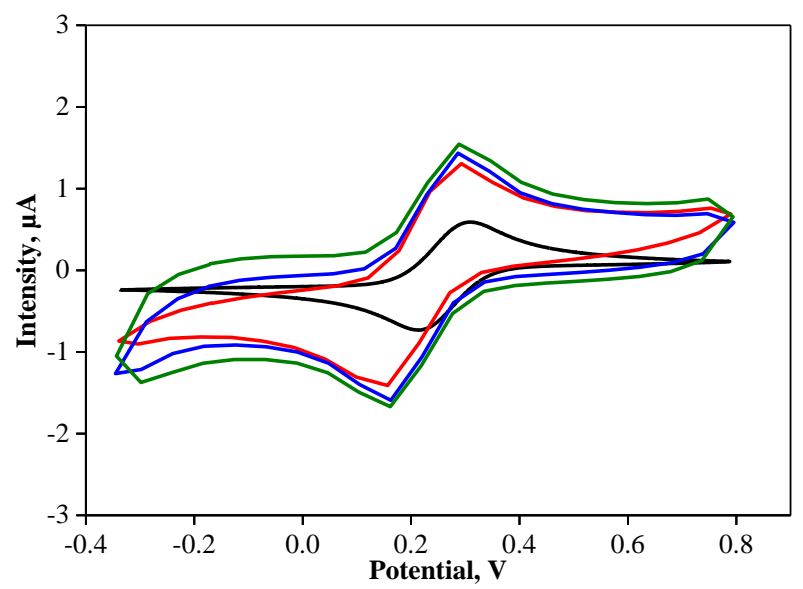

Fig. 5. The cyclic voltammograms of the gold disk electrode (black line), rGO (red line), Au/rGO-60 catalyst (blue line) and Au/rGO-80 catalyst (green line) at $50 \mathrm{mV} \cdot \mathrm{s}^{-1}$ scan rate

In Table 4, the ECSA was calculated for the potential range $-0.35-1 \mathrm{~V}$. It can be observed that Au/rGO-60 sample has a higher ECSA than Au/rGO-80 due to a higher pore volume and a specific surface.

Table 4. The SECSA of Au/rGO prepared samples

\begin{tabular}{|c|c|c|}
\hline \multirow{2}{*}{ Sample } & \multicolumn{2}{|c|}{ Electrochemical surface area, $\mathrm{cm}^{2}$} \\
\cline { 2 - 3 } & First cycle & 200 cycle \\
\hline $\mathrm{Au} / \mathrm{rGO}-60$ & $10.828 \times 10^{-3}$ & $11.998 \times 10^{-3}$ \\
\hline $\mathrm{Au} / \mathrm{rGO}-80$ & $8.35 \times 10^{-3}$ & $10.099 \times 10^{-3}$ \\
\hline
\end{tabular}

In Fig. 6 and Fig. 7 are presented the accelerated degradation test (AST) in the potential field of $-0.35-1.0 \mathrm{~V}$ vs $\mathrm{Ag} / \mathrm{AgCl}$.

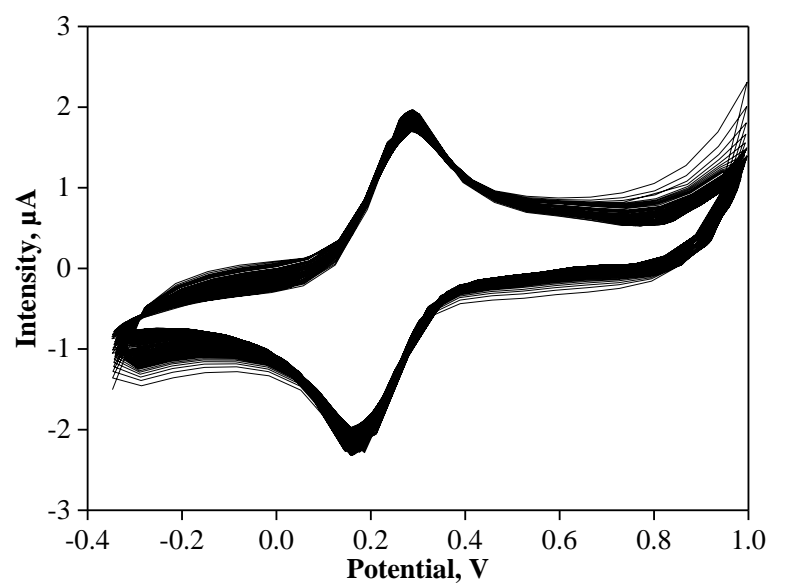

Fig. 6. The cyclic voltammograms of Au/rGO-60 catalyst after 200 cycles at $50 \mathrm{mV} \cdot \mathrm{s}^{-1} \mathrm{scan}$ rate

It is seen that the voltammograms obtained using $\mathrm{Au}$ based catalysts are almost identical and the recorded data became stable after tenth cycle [25]. After 200 cycles, the $\mathrm{CV}$ measurement show very good stability, proving a good repeatability of $\mathrm{Au}$ based catalysts. It can be observed that 
wider peaks are presented in the potential range $0.8-1.0 \mathrm{~V}$ and are assigns to the formation of gold hydroxide and oxide in the anodic scan as well as the corresponding reduction of gold oxide in the return sweep [24].

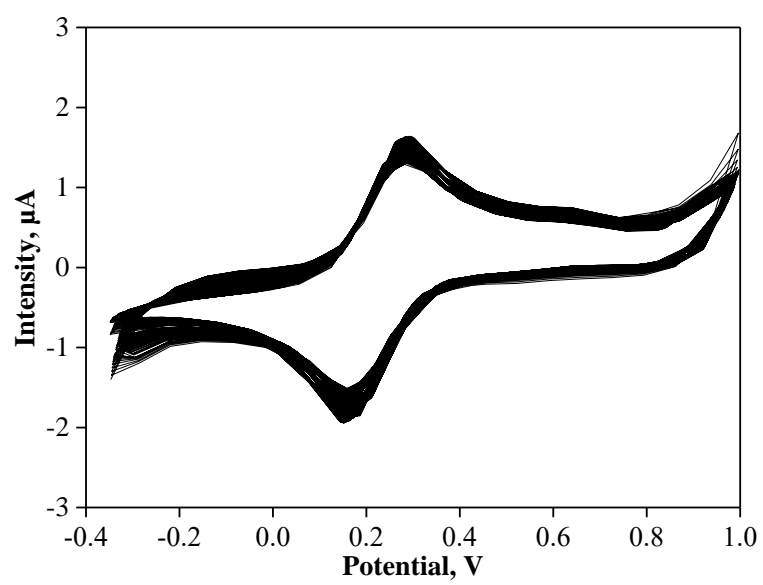

Fig. 7. The cyclic voltammograms of Au/rGO-80 catalyst after 200 cycles at $50 \mathrm{mV} \cdot \mathrm{s}^{-1} \mathrm{scan}$ rate

\section{CONCLUSIONS}

The using of microwave irradiation for synthesize graphene composites could be an advantage for many technologies in the energy domain such as fuel cells. Moreover, this technique proved to have some advantages being simple, quick, inexpensive and uniform, advantages that could be used more and more in the next future in order to synthesize various materials with controlled size and shape for the energy application.

In this work we have developed a facile, low time consuming, low cost and efficient method to prepare gold supported on reduced graphene oxide $(\mathrm{Au} / \mathrm{rGO})$. $\mathrm{Au} / \mathrm{rGO}$ samples were synthesized at microwave power of $800 \mathrm{~W}$ and two different reaction temperatures, 60 and $80^{\circ} \mathrm{C}$, for 30 minutes only. The physical characterizations of the samples have indicated the grafting of Au nanoparticles on the surface of graphene sheets. Additionally, the nitrogen adsorption-desorption isotherms show that at $60{ }^{\circ} \mathrm{C}$ a higher pore volume and a specific surface were obtained suggesting that a larger mesoporous volume and interconnections are presented in this sample, which favorized the mass transport process in PEMFC by creating a facile access of the reactants. The stability of prepared materials was evaluated by accelerated electrochemical stability test using a protocol involving multiple $\mathrm{CV}$ in potential range of $-0.35 \div 0.8$ and $0.35 \div 1.0 \mathrm{~V}$ vs. $\mathrm{Ag} / \mathrm{AgCl}$.

The good electrocatalytic activities of the samples were assigned to a mixture of benefits arising both from reduced graphene and the gold nanoparticles deposited on the support. The strong interactions between gold nanoparticles and rGO help to disclose the catalytically active sites, thus enhancing the charge transport through the rGO layers.

\section{Acknowledgments}

This work is supported by the National Agency of Scientific Research from Romania by the National Plan of
R \& D, Project No. 19110201 and PN-III-P-1.2-PCCDI2017-0194/25 PCCDI.

\section{REFERENCES}

1. Pham-Huu, C., Ledoux, M. Carbon Nanomaterials with Controlled Macroscopic Shapes as New Catalytic Materials Topics in Catalysis $40(1-4)$ 2006: pp. 49-63. https://doi.org/10.1007/s11244-006-0104-8

2. Allen, M.J., Tung, V.C., Kaner, R.B. Honeycomb Carbon: A Review of Graphene Chemical Reviews 110 2010: pp. $132-145$. https://doi.org/10.1021/cr900070d

3. Schnorr, J.M., Swager, T.M. Emerging Applications of Carbon Nanotubes Chemistry of Materials 23 2011: pp. 646-657. https://doi.org/10.1021/cm102406h

4. Wei, D.C., Wu, B., Guo, Y.L., Yu, G., Liu, Y.Q. Controllable Chemical Vapor Deposition Growth of Few Layer Graphene for Electronic Devices Account of Chemical Research 46 2013: pp. 106-115. https://doi.org/10.1021/ar300103f

5. Chen, W.F., Yan, L.F., Bangal, P.R. Preparation of Graphene by the Rapid and Mild Thermal Reduction of Graphene Oxide Induced by Microwaves Carbon 48 2010: pp. $1146-1152$. https://doi.org/10.1016/j.carbon. 2009.11.037

6. Luo, Z.T., Lu, Y., Somers, L.A., Johnson, A.T.C. High Yield Preparation of Macroscopic Graphene Oxide Membranes Journal of the American Chemical Society 131 2009: pp. $898-899$. https://doi.org/10.1021/ja807934n

7. Xiao, L.Q., Liao, L.Q., Liu, L.J. Chemical Modification of Graphene Oxide with Carbethoxycarbene under Microwave Irradiation Chemical Physics Letters 556 2013: pp. 376-379. https://doi.org/10.1016/j.cplett.2012.11.084

8. Hassan, H.M.A., $\quad$ Abdelsayed, V., Khder, A.E.R.S., AbouZeid, K.M., Terner, J., El-Shall, M.S., AlResayes, S.I., El-Azhary, A.A. Microwave Synthesis of Graphene Sheets Supporting Metal Nanocrystals in Aqueous and Organic Media Journal of Materials Chemistry 19 2009: pp. $3832-3837$. https://doi.org/10.1039/B906253J

9. Guo, S.J., Wen, D., Zhai, Y.M., Dong, S.J., Wang, E.K. Platinum Nanoparticle Ensemble-on-Graphene Hybrid Nanosheets: One-Pot, Rapid Synthesis, and Used as New Electrode Material for Electrochemical Sensing American Chemical Society Nano 4 2010: pp. 3959-3968. https://doi.org/10.1021/nn100852h

10. Yan, J., Wei, T., Qiao, W., Shao, B., Zhao, Q., Zhang, L., Fan, Z. Rapid Microwave-Assisted Synthesis of Graphene Nanosheets $/ \mathrm{Co}_{3} \mathrm{O}_{4}$ Composite for Supercapacitors Electrochimica Acta 55 2010: pp. 6973-6978. https:// doi.org/10.1016/j.electacta.2010.06.081

11. Galema, S.A. Microwave Chemistry Chemical Society Reviews 26 1997: pp. 233-238. https:// doi.org/10.1039/ CS9972600233

12. Siamaki, A.R., Khder, A.E.R.S., Abdelsayed, V., El-Shall, M.S., Gupton, B.F. Microwave-Assisted Synthesis of Palladium Nanoparticles Supported on Graphene: A Highly Active and Recyclable Catalyst for Carbon-Carbon Cross-Coupling Reactions Journal of Catalysis 279 2011: pp. 1-11. https://doi.org/10.1016/ j.jcat.2010.12.003 
13. Hu, H., Zhao, Z.B., Zhou, Q., Gogotsi, Y., Qiu, J.S. The Role of Microwave Absorption on Formation of Graphene from Graphite Oxide Carbon 50 2012: pp. 3267-3273. https://doi.org/10.1016/j.carbon.2011.12.005

14. Thostenson, E.T., Chou, T.W. Microwave Processing: Fundamentals and Applications Composites Part A: Applied Science and Manufacturing 30 1999: pp. $1055-1071$. https://doi.org/10.1016/S1359-835X(99)00020-2

15. Tang, P., Hu, G., Gao, Y., Li, W., Yao, S., Liu, Z., Ma, D. The Microwave Adsorption Behavior and MicrowaveAssisted Heteroatoms Doping of Graphene-Based NanoCarbon Materials Scientific Reports 4 2014: pp. $5901-5907$. https://doi.org/10.1038/srep05901

16. Kappe, C.O. Controlled Microwave Heating in Modern Organic Synthesis Angewandte Chemie International Edition 43 2004: pp. 6250-6284. https://doi.org/10.1002/ anie.200400655

17. Roberts, B.A., Strauss, C.R. Toward Rapid, "Green", Predictable Microwave-Assisted Synthesis Accounts of Chemical Research 38 2005: pp. 653-661. https://doi.org/10.1021/ar040278m

18. Gao, Y.J., Ma, D., Wang, C.L., Guan, J., Bao, X.H. Reduced Graphene Oxide as a Catalyst for Hydrogenation of Nitrobenzene at Room Temperature Chemical Communications 47 2001: pp. 2432-2434. https://doi.org/10.1039/ C0CC04420B

19. Gao, Y.J., Hu, G., Zhong, J., Shi, Z., Zhu, Y., Su, D.S., Wang, J., Bao, X., Ma, D. Nitrogen-Doped $\mathrm{sp}^{2}$-Hybridized Carbon as a Superior Catalyst for Selective Oxidation Angewandte Chemie International Edition 52 2013: pp. 2109-2113. https://doi.org/10.1002/anie.201207918
20. Imholt, T.J., Dyke, C.A., Hasslacher, B., Perez, J.M., Price, D.W., Roberts, J.A., Scott, J.B., Wadhawan, A., Ye, Z., Tour, J.M. Nanotubes in Microwave Fields: Light Emission, Intense Heat, Outgassing, and Reconstruction Chemistry of Materials 15 2003: pp. 3969-3970. https://doi.org/10.1021/cm034530g

21. Chen, J., Jiang, C., Yang, X., Feng, L., Gallogly, E.B., Wang, R. Studies on how to Obtain the Best Catalytic Activity of Pt/C Catalyst by Three Reduction Routes for Methanol Electro-Oxidation Electrochemistry Communications 13 2011: pp. 314-316. https://doi.org/ 10.1016/j.elecom. 2011.01.012

22. Kim, P., Joo, J.B., Kim, J., Song, I.K., Yi, J. NaBH4Assisted Ethylene Glycol Reduction for Preparation of Carbon-Supported $\mathrm{Pt}$ Catalyst for Methanol ElectroOxidation Journal of Power Sources 160 2006: pp. $987-990$. https://doi.org/10.1016/j.jpowsour.2006.02.050

23. Suh, W., Ganesan, P., Son, B., Kim, H., Shanmugam, S. Graphene Supported Pt-Ni Nanoparticles for Oxygen Reduction Reaction in Acidic Electrolyte International Journal of Hydrogen Energy 41 2016: pp. 12983-12994. https://doi.org/10.1016/j.ijhydene.2016.04.090

24. Govindhan, M., Chen, A. Simultaneous Synthesis of Gold Nanoparticle/Graphene Nanocomposite for Enhanced Oxygen Reduction Reaction Journal of Power Sources 274 2015: pp. $928-936$. https://doi.org/10.1016/j.jpowsour. 2014.10.115

25. Wang, F.B., Wang, J., Shao, L., Zhao, Y., Xia, X.H. Hybrids of Gold Nanoparticles Highly Dispersed on Graphene for the Oxygen Reduction Reaction Electrochemistry Communications 35 2014: pp. 82-85. https://doi.org/10.1016/j.elecom.2013.11.005 